\title{
Application of Multi-lens Video Editing Technology in Multi-media Interactive Teaching of "Aerobics"
}

\author{
https://doi.org/10.3991/ijet.v12i02.6484 \\ Xiaoyan Zhong \\ Hunan First Normal University, Changsha, China \\ xiaoyanzhong 12 @yeah. net
}

\begin{abstract}
This study designed an interactive multi-media remote courseware teaching system based on the network application technology Flex and the multi-media server technology FMS. It can quickly extract and concatenate scattered images and videos in teaching courseware, and then generate complete and clear materials of teaching courseware. Meanwhile, by using the network server constructed on FMS, the system can realize remote interactive design and teaching application online. Noticeably, the system is featured by its diversified functions such as remote login, live teaching of courseware and interactive video-based teaching. After the system was applied in teaching of "aerobics" in a comparative experiment, it was also found that: the system's interactive teaching function has a significant effect on enhancing students' interest in multi-media teaching, strengthening their mastery of the teaching content and improving their achievements in practice assessments.
\end{abstract}

Keywords - Interactive design, video editing, Flex + FMS technology, aerobics

\section{$1 \quad$ Introduction}

Interactive multi-media courseware teaching system is a kind of multi-media technology-based information teaching platform which integrates network technology, database technology and interactive sharing technology. The platform can provide teachers and learners with integrated interactive access, learning, assessment and other functional experience, and move the traditional teaching process to the network teaching platform to achieve the interaction effect of teaching [1]. Multimedia interactive technology is an emerging technology which is constantly developing, progressing and increasingly perfect. In view of its advanced nature and modernity, this kind of teaching system has quickly replaced traditional approaches of collecting information and conforms to the requirement of rapid development in the information age. At present, multi-media interactive technology as a teaching aid is gradually replacing traditional teaching methods [2]. 
Paper-Application of Multi-lens Video Editing Technology in Multi-media Interactive Teaching of "Aerobics"

Du el al. cleverly applied somatosensory interaction system to multi-media teaching. They used the strong bone tracking function of Kinect to control slideshow through limb movements, thereby bringing great convenience to the teaching pattern. The experiment also found that this multi-media interactive technology can significantly increase the interaction between teachers and students to improve the teaching atmosphere in classroom [3]. Xiao et al. discussed a number of interactive techniques commonly adopted in the design of interactive multi-media courseware such as mouse click type, mouse drag type, text input type and keyboard press type, and used Flash and Action Script 3.0 scripting language to design the multi-media interactive courseware for "distance between two points", offering the specific effect of interactive multi-media courseware [4]. Zhang integrated VBA technology into Powerpoint, making it possible to produce human-computer interactive multi-media courseware by Powerpoint. After the user answers on a slide, PowerPoint can compare the user's answer with the standard answer. This method plays an important role for the production of high-quality teaching courseware [5]. Toro gave explanation over the implementation of event-driven real-time interpreters for the Nondeterministic Timed Concurrent Constraint (NTCC) for- malisms and Concurrent Constraint Programming (CCP). In addition to testing the CCP interpreter with a program, Toro suggested the future use of paths in a graph to find musical sequences in the music improvisation software Omax, created by the French Acoustics/Music Research Institute (IRCAM) [6]. A method of using arousal evaluation and an eye movement activity was put forward by Ekanayake (2015) to identify the psychological involvement of a human interaction. The low cost combination of software and hardware was used to determine the level of arousal using galvanic skin response GSR) signals and eye movement activity based on electrooculogram (EOG) signals. The results of testing six participants reveal that these affecting signals such as disabling conditions and optimal levels can be employed to recognize the nature of involvement [7].

On the whole, teaching interaction is the core of modern distance education [8]. Interaction in distance education refers to mutual exchange and interaction between distance learners and all distance education resources, including the exchange and interaction among distance learners, learning materials and tutors. For distance education, teaching interaction mediated by a variety of media is the key to achieve re-integration of teaching and learning. Therefore, the level of teaching interaction directly reflects the level of teaching, and also directly affects the effect of learning. However, there are some shortcomings in the production of interactive courseware, as discovered by the existing researches. First of all, in order to obtain a wealth of shooting materials and facilitate the subsequent courseware editing, the traditional courseware production often adopts multi-lens shooting. Usually, the courseware material shot via a single lens is displayed. In the editing process, after previewing the courseware material obtained by a single lens, the user needs to switch the lens material to preview the next lens material. Generally, it is difficult for teachers to determine which lens material is demanded for the time being. Therefore, they should constantly preview different lens materials before identifying the lens material required, which requires repeated quite cumbersome operations of switching the lens 
material. For an ordinary teacher, it is hard to grasp this complex operating technique, resulting in low working efficiency [9]. Secondly, in the past, "aerobics" or other specialized sports courses basically uses conventional multi-media PPT courseware display, or direct demonstration of videos [10]. Meanwhile, it is rare that interactive technology and multi-media teaching are combined for teaching "Aerobics" courses in universities and colleges.

In view of the shortcomings mentioned above, this study developed a multi-lens video editing technology. On the one hand, it achieves technical innovation: a video editing method targeted at multi-lens video material and a corresponding video editing device for multi-lens video material can extract one or more video segments designated by the user during the process of playing the video material. The extracted one or more video segments would be spliced into a complete video according to the shooting time sequence. At the same time, the user can quickly determine and select the needed lens video material and greatly improve the efficiency of editing teaching videos in the editing process. The innovation of the technology is also reflected in the aspect of application: First of all, it can be applied in multi-media teaching courseware production. Because "aerobics" a practice-based teaching course for the major of sports in universities and colleges, the use of distance multi-media interactive teaching is quite innovative. This teaching experiment was expected to provide some reference for the research in this field.

\section{Theoretical Construction of Interactive Multi-media Courseware Teaching System}

As aforementioned, teaching interaction is the core of modern distance education. Interaction in distance education refers to mutual exchange and interaction between distance learners and all distance education resources, including the exchange and interaction among distance learners, learning materials and tutors. For distance education, teaching interaction mediated by a variety of media is the key to achieve re-integration of teaching and learning. Therefore, the level of teaching interaction directly reflects the level of teaching, and also directly affects the effect of learning.

\subsection{Principle of interactive multi-media courseware design}

The multi-media production software Anchorage is applied in the system [11]. The software has some obvious advantages in producing teaching courseware, because it has a huge material library and covers shading, wallpaper, sound, etc. which are frequently used in the process of creating teaching courseware. A variety of file formats can be in operated Anthorware, thus greatly facilitating the collection of materials. A large amount of materials can be collected and stored by the production staff, and the content of the material library is gradually enriched. It is fast and easy to carry different carriers. Video is an important part of multi-media courseware. The user can choose to transform video clips shot by multi-lens video editing into avi files. If video resources and photos taken at the scene can be effectively used, courseware 
materials can be greatly enriched, while the production cost can be reduced accordingly. Figure 1 shows the process for the production staff to set the size and background color of the multi-media CD-ROM window through the path: modify-> file-> properties. The system will pop up the following dialog box of properties. After selecting the size needed, the user can click the box next to background. Then, the system will pop up the color box, for the user to choose the appropriate background color according to the teaching content and students' demand.

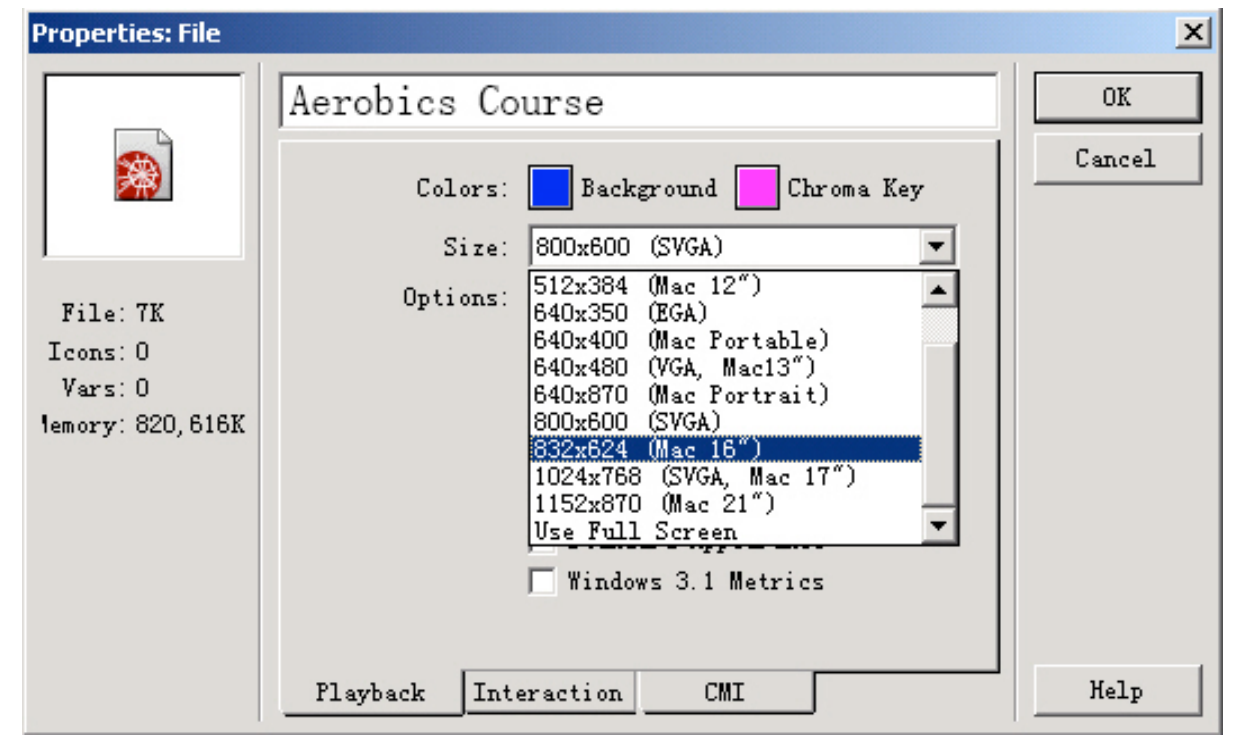

Fig. 1. Steps for interactive multi-media courseware design

\subsection{Basic idea of design of interactive multi-media courseware design}

For example, the design principle of the "aerobics" course in this study has produced its own unique expression language in the process of "moving". Continuous display and frame-by-frame play are the essential attributes of animation illustration. These attributes determine the difference between the teaching method and that of other majors, as well as the final transmission way of playing motion images like aerobics. The video and picture materials used in the course are completed in the connection of individual pictures. In other words, a series of static frame modeling form movement under the condition of superposition and counterpoint. Screen shape and many other functions must be achieved in continuous movement. The scientific and expressive nature of the language offers the most intuitive and the most visual method for dynamic image to convey the course.

In this study, several sets of video clips, illustrations and teaching cases of the aerobics course were prepared in advance. The main function of the motion detector was used to combine multi-media interactive technology with the teaching content of 
Paper-Application of Multi-lens Video Editing Technology in Multi-media Interactive Teaching of "Aerobics"

the course to integrate resources and to introduce the system into classroom. The system was also aided by the PPT design principle usually used in the past to design some contents, such as classroom teaching mode, curriculum, syllabus, teaching plan and so on.

\section{Design of Interactive Multi-media Courseware}

\subsection{Design of login module}

Based on the specific needs of distance online teaching of the course, the system's login module consists of two parts: student-controlled mode and teacher-controlled mode. Figure 2 shows the concrete module design.

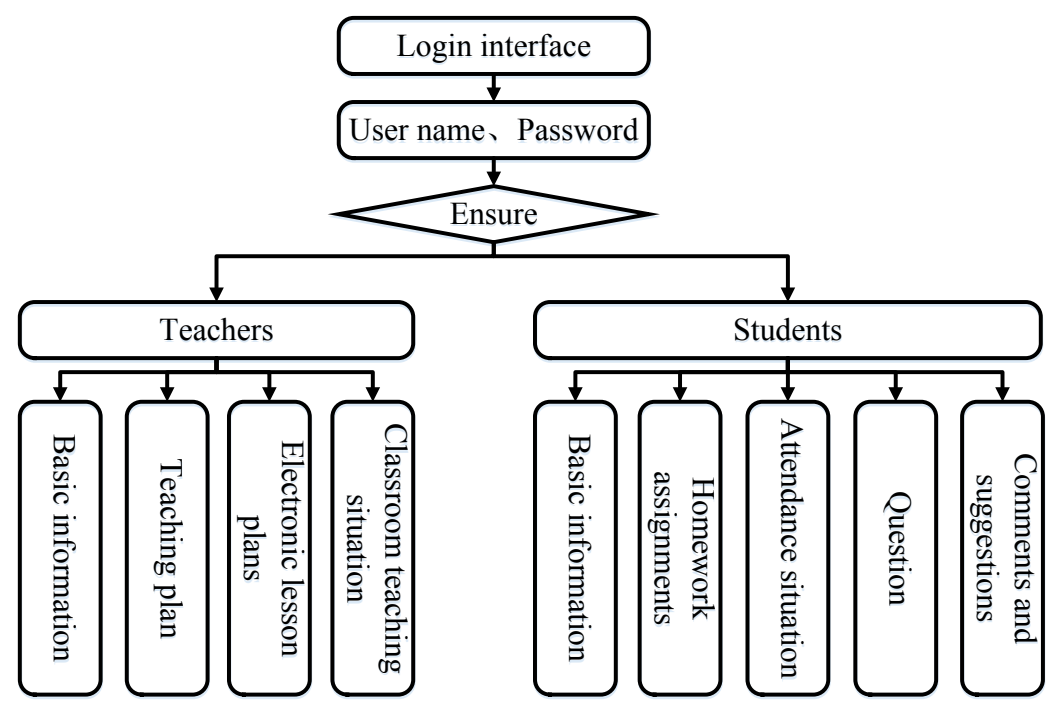

Fig. 2. Design of the system's login module

In the development of the system's login module, it was necessary to apply Flex technology to design two permission login interfaces. During the login process, teachers and students need to input their corresponding login name and password according to their own permission.

\subsection{Design of video editing and live broadcasting module}

Video editing and live broadcasting module is the core part of this system. The primary function of this part is to edit multi-lens video and animation materials in the courseware. In the concrete implementation, the sequence is edited in the window to 
be displayed. The materials of different course contents are added to different editing tracks in the form of video or animation. According to the sequence of courseware production, all the materials are spliced into a complete courseware section. This can greatly enhance the efficiency of video editing and live broadcasting.

As shown in Figure 3, at the service terminal, the teacher can edit and product useful courseware materials through the process above, and upload courseware materials to the backstage by empowering the system. In the process above, it is necessary to apply MXML in Flex to mark the front interface of language editing video display, and also use ActionScript for compilation of the backstage console. In the actual courseware display process, an external camera and microphone should be used for live broadcasting of interactive teaching.

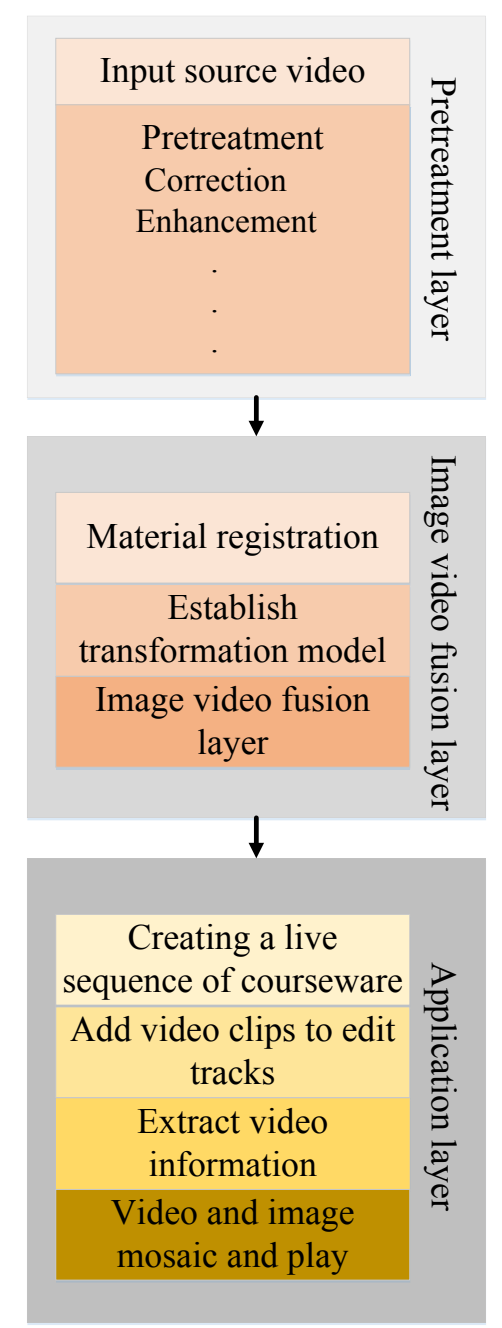

Fig. 3. Design of video editing and live broadcasting module 


\subsection{Design of courseware interactive teaching module}

When using interactive courseware module, the teacher can watch videos of students' practical work online, communicate with students in real time, and point out the advantages and disadvantages of their aerobics, while students can immediately engage in rectification and show new actions to the teacher. The design principle is: Students use the local camera to capture the learning interface, and upload it to the teacher terminal through the FMS virtual server; the teacher utilizes the video player to watch it and applies the SharedObject object frame built based on Flex technology after watching to chat with students in text. At the same time, in the server constructed on FMS, the teacher and students can use the camera and microphone to have an interactive chat, or enjoy textual communication through the online interactive teaching whiteboard built in the system.

It can be seen in Figure 4 that the whole interactive teaching process focuses on FMS server. Personal information of teachers and students is illustrated in the USER1, USER2 and USER3 form. The participants can, take part in online interactive teaching through the front interface built based on the server and Flex.

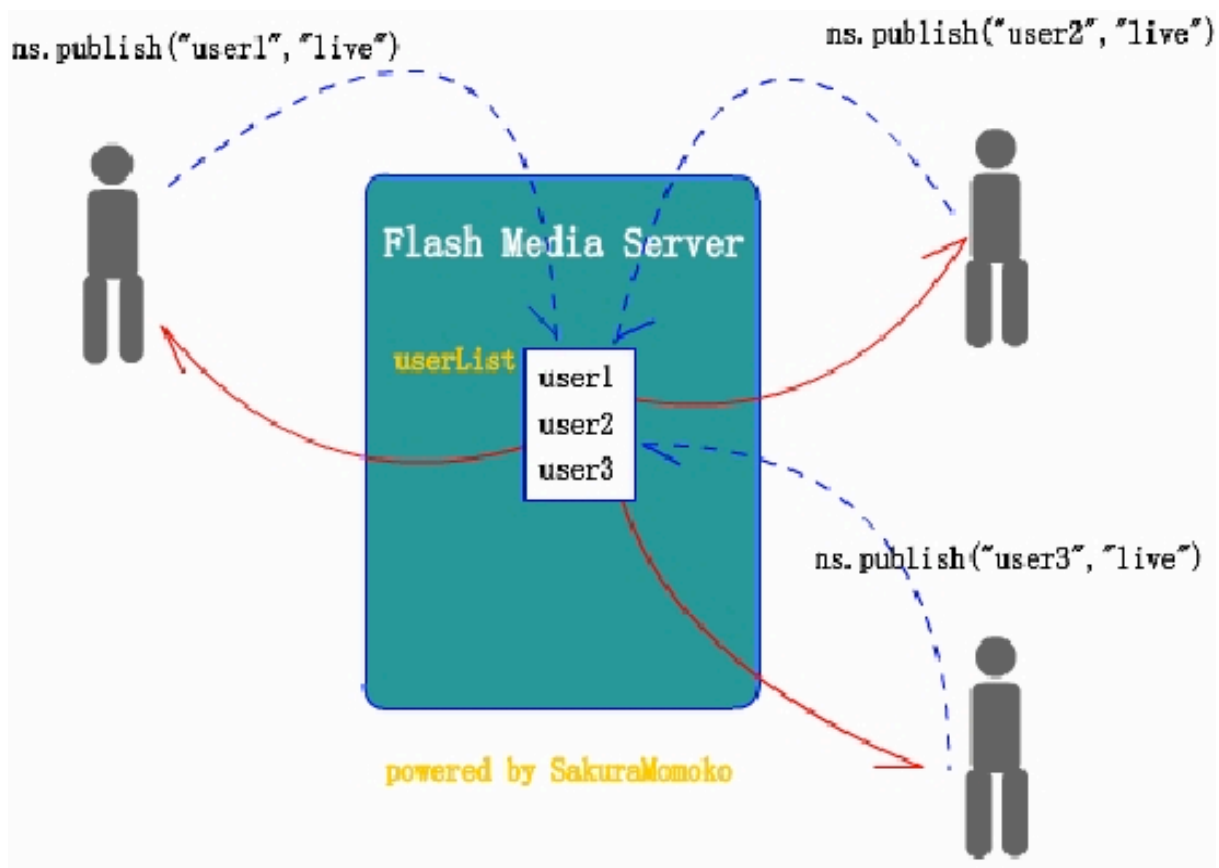

Fig. 4. Schematic diagram of courseware interactive teaching 


\subsection{Design of FMS server's configuration}

FMS server is the transfer station of the system used for communication of courseware, video, animation teaching information. At the beginning of designing the system, the user is required to download FMS4.5 from Adobe's official website and utilize it to build a virtual server which supports the teaching platform. The specific configuration process is as follows:

Installation and configuration after downloading FMS4.5: Log on the official website, download FMS4.5 software and follow the prompts to finish installation and configuration. Figure 5 gives the screenshot of installation.

Starting FMS4.5 server: As shown in Figure 6, Click [Start] $\rightarrow$ [Programs] $\rightarrow$ [Adobe] $\rightarrow$ [Flash Media Server 4.5] $\rightarrow$ [Start Flash Media Administration Server 4.5] to start the server.

Setting the address of FMS4.5 server: Setting the server address is helpful for using the entire teaching system to change the address for mutual connection and thereby to achieve sharing, downloading and uploading of courseware information. The address of the server for the system designed in this study is: 218.89.107.69. After setting the address, the user can try playing a piece of video coming with the server.

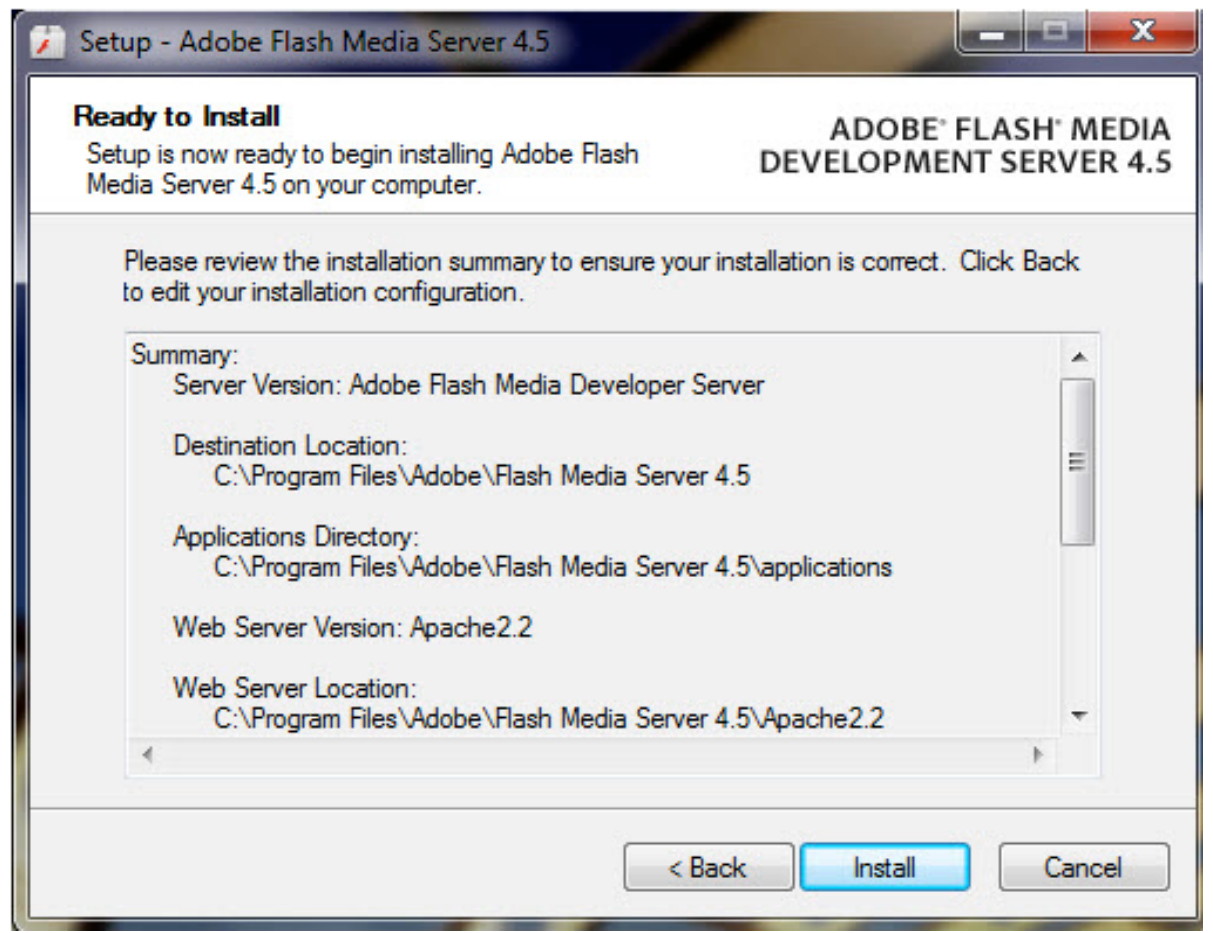

Fig. 5. Screenshot of installing FMS4.5 server 


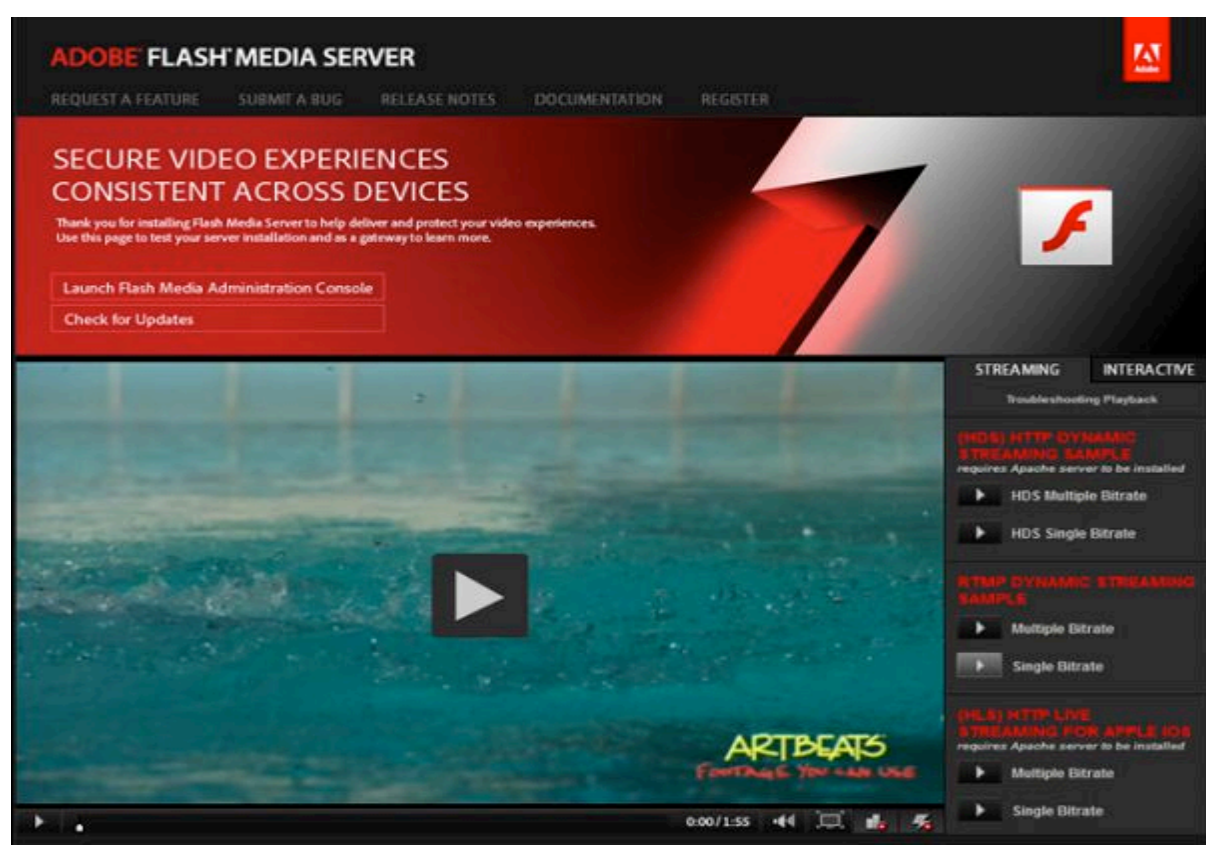

Fig. 6. Screenshot of starting FMS4.5 server

\subsection{Design of database}

This system adopts SQL Server 2005 as the database system. To meet the design requirement, the database scale of the system includes: the basic courseware module information table (Functions), the basic user information table (Users) and the courseware resource table (Resources). Specifically, the basic courseware module information table (Functions) is mainly used for storing data information of all submodules of the system. The basic user information table (Users) is primarily utilized for collecting the information such as the user's login name and password; the courseware resource table (Resources) aims to store videos, animations, texts and teaching resources exchanged between teachers and students online.

\section{Implementation of Interactive Multi-media Distance Courseware Teaching System}

\subsection{Implementation of login module}

According to the design idea discussed previously, the system's login module mainly includes the user name input and password input interface. After design, the 
system's login interface uses Flex to produce the front visualized interface. The specific programming idea is: MXML of Flex is used to make the login page. Firstly, a Panel container is placed, followed by the application of ActionScript to compile the background support system, including the login text box input system, login password modification system and so on.

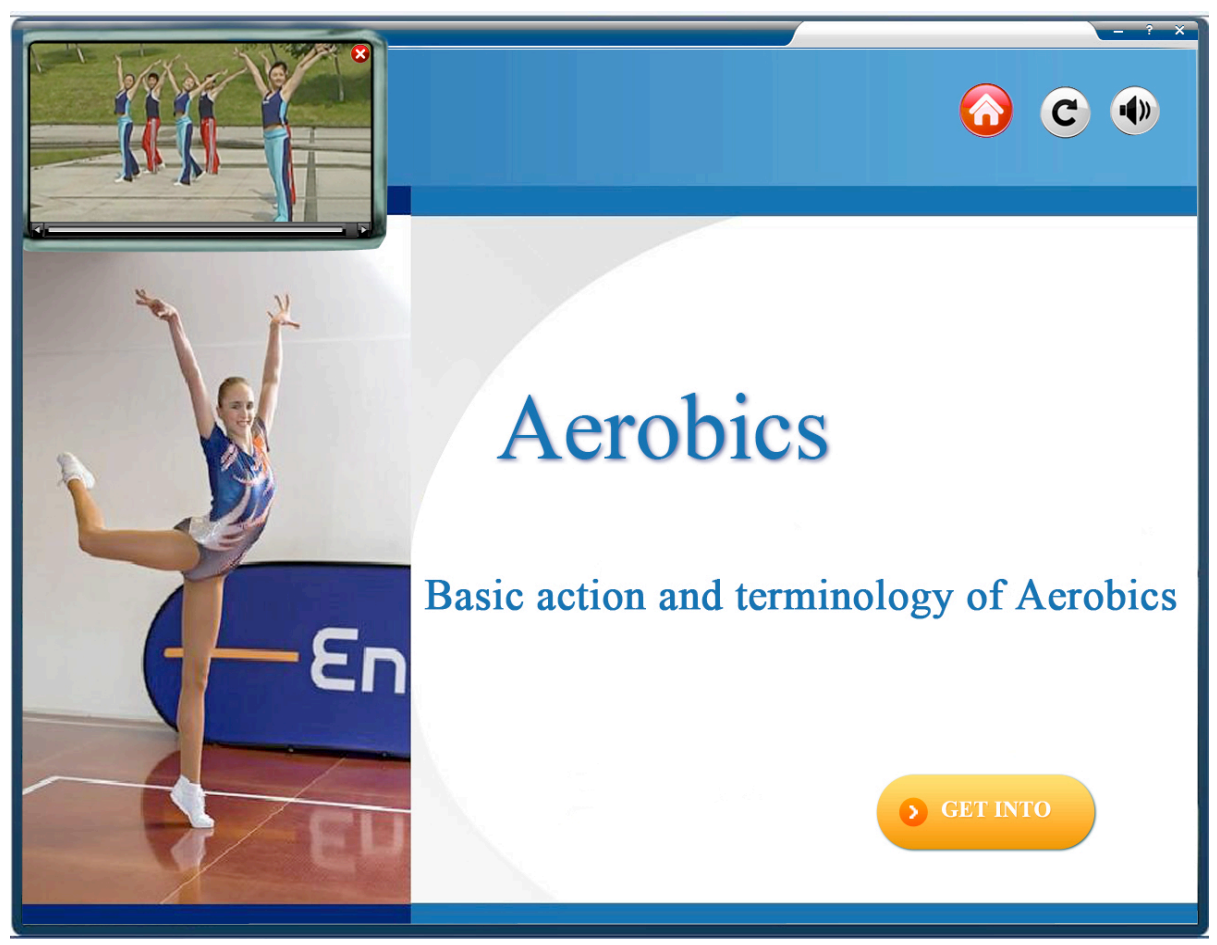

Fig. 7. Live recording and broadcasting interface of multi-media interactive technology

\subsection{Implementation of video editing and live broadcasting module}

Three steps are required for the implementation of video editing and live broadcasting module. Firstly, the system will automatically get access to the camera and microphone at the teacher terminal and the student terminal, and initialize the settings. Secondly, the connection state of FMS is detected to determine whether data communication within the system is normal. Finally, after the communication detection is completed, it comes to live broadcasting of teaching videos. In this step, the user can enjoy independent editing. Figure 7 demonstrates the live broadcasting interface of multi-media interactive technology. 


\subsection{Implementation of courseware interactive teaching module}

Under the condition of smooth communication, the teacher and students can engage in interactive teaching after logging on the system. The ways of realizing interaction include text chatting, voice chatting and handwriting chatting via the interactive teaching whiteboard. Among them, interactive teaching whiteboard is one kind of Internet-based handwriting interactive software, covering free brush, color selection, content clearing and other functions.

\section{Cases of Application in Teaching}

After the system was designed, class (1) and class (2) of Grade 2014 majoring in sports in School of Physical Education in Hunan First Normal University were selected as the objects of teaching in the comparative teaching research. Both classes were composed of 35 students. In the specific teaching implementation, class (1) was treated as the experimental class, while class (2) was the control class. For the control class, the traditional training mode of teaching was adopted, and the final examination was also based on the traditional one-to-one presentation. For the experimental class, the teacher used the courseware made by multi-lens video editing technology in multimedia teaching. After 30 hours of teaching, the teacher collected learning effect indicators of students in the two classes for the quantified statistical comparison.

Table 1. Statistical Results Of The Final Examination

\begin{tabular}{lccc}
\hline \multicolumn{1}{c}{ Class } & $\mathbf{N}$ & $\begin{array}{c}\text { Average score in theory } \\
\text { examination }\end{array}$ & $\begin{array}{c}\text { Average score in practice } \\
\text { examination }\end{array}$ \\
\hline Experimental class & 35 & 89.2 & 95.3 \\
Control class & 35 & 67.5 & 71.2 \\
\hline
\end{tabular}

Table 2. Statistical Results Of Students' Learning Experience

\begin{tabular}{llcc}
\hline \multicolumn{1}{c}{ Experience item } & \multicolumn{1}{c}{ option } & Control group \% & Experimental group \% \\
\hline \multirow{2}{*}{ Interest in course } & Very interested & 30 & 60 \\
learning & Interested & 25 & 30 \\
& Not interested & 45 & 10 \\
\multirow{4}{*}{ Seriousness towards } & Very serious & 35 & 65 \\
teaching & Not serious occasionally & 40 & 30 \\
& Often not serious & 25 & 5 \\
\multirow{2}{*}{$\begin{array}{l}\text { Mastery of aerobics } \\
\text { movements }\end{array}$} & Skilled & 45 & 75 \\
& general & 35 & 20 \\
\hline
\end{tabular}

"Aerobics" is a compulsory course of physical education in colleges and universities. This course places emphasis on training and practicing, and requires students to master practical training skills of aerobics through long-term exercise. Under the traditional teaching mode, teachers generally adopt the "theory + practice" approach 
Paper-Application of Multi-lens Video Editing Technology in Multi-media Interactive Teaching of "Aerobics"

to carry out teaching. This teaching mode is more mature, but old-fashioned, resulting in the difficulty to really stimulate students' interest in learning. This study designed an interactive multi-media distance courseware teaching system based on Flex + FMS. The system can integrate a lot of "aerobics" courseware videos, animations and text lesson plans, and could realize distance online interactive learning. With the help of this online teaching system, teachers can constructed their online teaching system and move aerobics training to the Internet, greatly improving the dynamic and advanced nature of teaching. In addition, the front-end interface developed by using Flex technology and the communication server built by FMS allow teachers and students to have online learning exchange, dynamic visits, downloading and uploading of courseware resources and other activities, which is conducive to real-time feedback of teaching and sharing of teaching results.

Teaching comparison based on Table 1 and Table 2 also revealed that students of the experimental class obtained an average of 95.3 points in the training assessment, but their counterparts in the control class got only 71.2 points. In terms of interest in learning, seriousness towards teaching, mastery of aerobics movements and other indicators of learning effect, students in the experimental class were significantly better than students in the control class. Throughout this research, it was found that when teachers use the traditional teaching mode to help students understand and study relevant aerobics movements, they are faced by certain restrictions, which leads to the slow progress and narrow scope of teaching and limits the expansion of the teaching information. Besides, some young teachers' movements are not standardized, resulting in low credibility of knowledge explanation. Nevertheless, the system can provide students with dynamic display of each standardized decomposed movement of aerobics to enhance students' understanding and interest; for teachers, the system could also reduce their workload and improve their own business ability, so that teachers and students can form a teaching and learning initiative and participation awareness. The subsequent increase in students' mastery aerobics would contribute to improvement of their overall learning achievement.

\section{Conclusion}

The study explored the positive value of the application of this system in promoting course teaching quality of "aerobics". Therefore, the system should be widely applied other courses of physical education in universities and colleges. This study used Flex + FMS technology to design an interactive multi-media distance courseware teaching system, which also plays an important role in enhancing the teaching effectiveness of "aerobics". In the future teaching reform, we should introduce more computer information technologies and build a professional multi-media distance learning platform to bring more information elements into course teaching. 


\section{$7 \quad$ References}

[1] Mantiri. F. "Multimedia and Technology in Learning," Universal Journal of Educational Research, vol. 2, no. 9, pp. 589-592, September 2014.

[2] Sugar, W. "Development and formative evaluation of multimedia case studies for Instructional Design and Technology students," Techtrends Linking Research \& Practice to Improve Learning, vol. 58, no. 5, pp. 36-52, September 2014. https://doi.org/10.1007/s11528014-0785-z

[3] Du, X.H., Li, Y.H., Feng, Y., et al. "Application of kinect-based somatosensory interactive system in multi-media teaching," Computer CD Software and Applications, no. 2, pp. 202203, March 2014.

[4] Xiao, Y., Qian, B. "Design and Implementation of Interactive Multi-media Courseware Based on Flash and Action3.0," Computer Knowledge and Technology, vol. 12, no. 10, pp. 222-223, June 2016.

[5] Zhang, J., Li, L.L., Feng, J.H. "Introduction of VBA technology into Powerpoint to produce interactive multi-media courseware," Computer Knowledge and Technology, no. 5, pp. 1063-1065, March 2014.

[6] Toro, M. "Towards non-threaded Concurrent Constraint Programming for implementing multimedia interaction systems," arXiv preprint arXiv, 1510.03057, October 2015.

[7] Ekanayake, H.B., Karunarathna, D.D., Hewagamage, K.P. "Determining the Psychological Involvement in Multimedia Interactions," International Journal on Advances in Ict for Emerging Regions, vol. 2, no. 1, pp. 11-20, February 2015.

[8] Zhuhadar, L., Yang, R., Lytras, M.D. "The impact of Social Multimedia Systems on cyberlearners", Computers in Human Behavior, vol. 29, no. 2, pp. 378-385, March 2013. https://doi.org/10.1016/j.chb.2012.09.009

[9] Liang, F.W. "Discussion on montage of materials in the production of multi-media audiovisual teaching courseware," Modern Educational Technology, vol. 19, no. s1, pp. 236238, March 2009.

[10] Pan, L.L. "Design and production of Aerobics multi-media courseware," Electronic Test, no. 12, pp. 148-149, July 2014.

[11] Yao, C.C.J., Chang, H.H., Chang, J.Z.C., Lai, H.H., Lu, S.C., \& Chen, Y.J. "Revisiting the stability of mini-implants used for orthodontic anchorage," Journal of the Formosan Medical Association, vol. 114, no. 11, pp. 1122-1128, November 2015. https://doi.org/10.1016/j.jfma.2014.08.001

\section{Author}

Xiaoyan Zhong (Corresponding author) is a Lecturer in Physical Education Institute, Hunan First Normal University, Changsha 410205, China. Her research interests include college physical education and offline education (xiaoyanzhong12@yeah.net)

Article submitted 03 December 2016. Published as resubmitted by the author 23 January 2017. 